\title{
Infundebulectomy in management of uterine artery or uterine wall injury during complicated and difficult caesarean section: case series study
}

\author{
Abo B. A. Mitwally* \\ Department of Obstetrics and Gynecology, Women Health Hospital, Faculty of Medicine, Assiut University, Assiut, \\ Egypt
}

Received: 05 December 2021

Revised: 08 January 2022

Accepted: 11 January 2022

\section{*Correspondence:}

Dr. Abo B. A. Mitwally,

E-mail: Mitwally@aun.edu.eg

Copyright: $\odot$ the author(s), publisher and licensee Medip Academy. This is an open-access article distributed under the terms of the Creative Commons Attribution Non-Commercial License, which permits unrestricted non-commercial use, distribution, and reproduction in any medium, provided the original work is properly cited.

\section{ABSTRACT}

It is case series trying to save uterus in situation where one site of it is severely injured or in severe uncontrollable bleeding in one of the uterine arteries either during control of massive hemorrhage associated with friable tissues with severe adhesion, some cases of placenta accrete spectrum, some cases of uterine rupture and in caesarean section myomectomy.

Keywords: Cesarean section, Rupture uterus, Post postpartum hemorrhage

\section{INTRODUCTION}

Caesarean section (CS) rates has been increased markedly all over the world, but in our developing countries with low facilities of neonatal care and monitoring fetal conditions during normal labor, now most of the obstetricians and patients prefer CS over normal vaginal delivery to avoid litigations due to suspected neonatal complication that increased due to highly increase in antenatal maternal and fetal complications, and also to avoid prolonged follow up of normal vaginal delivery as most of CSs were done in elective way.

In spite of recent awareness of populations in dour developing countries by a very high incidence of disadvantages of repeat CSs especially placenta acrreta spectrum and infections and increased rates of ended sequel by hysterectomy and associated morbidities, the number of CS was increasing continuously and markedly.
Multiple caesarean deliveries are associated with more difficult surgeries with increased blood loss. The risk of major complications increase with caesarean delivery number. ${ }^{1}$ Scaring and adhesion formation is known to cause increase in the complications depending up on the number of previous $\mathrm{CS}^{2}$

In the study done by Amale et al, the incidence of Intraoperative complications were more in repeat CS $(5.20 \%)$ as compared to primary CS (2.46\%) and difference was statistically significant. ${ }^{3}$

\section{CASE SERIES}

Total number of cases was 25 .

The study were done in Women Health Hospital, Assiut University, clinical private centers in Assiut governorate during Last four and half years starting from January 2016up till now September 2021 as following description: uterine artery rupture especially at left side (4 cases); 
severe pelvic adhesion during tracing suspected missed intra uterine contraceptive device (IUCD) in the peritoneal cavity in a patient with previous 3 CS (1 case); in trial of control of severe bleeding during CS due to injury to uterine artery either during trial of ligation to control postpartum hemorrhage, or its accidental injury during suturing extended of CS wound (17 cases) (most common case highlighted $(\neq)$ in Table 1 and Figures $1-3)$; during management of case of placenta acrreta spectrum (placenta percrreta with lateral involvement of left myometrial wall with big defect in the wall and in these cases ( 2 cases) exploration of ureter in left side and ligation of anterior division of internal iliac artery in left side and all efforts were done to conserve the uterus; and during bilateral uterine artery ligation to minimize blood loss may resulting from myomectomy after CS myomectomy (1 case) (Figures 4 and 5).

Table 1: Base line criteria of cases.

\begin{tabular}{|l|ll|l|}
\hline No. & Age & $\begin{array}{l}\text { No. } \\
\text { of CS }\end{array}$ & Case type \\
\hline 1 & 25 & 3 & $\neq$ \\
\hline 2 & 26 & 2 & $\neq$ \\
\hline 3 & 30 & 3 & $\neq$ \\
\hline 4 & 22 & 1 & $\neq$ \\
\hline 5 & 32 & 4 & $\neq$ \\
\hline 6 & 37 & 5 & Uterine wall rupture \\
\hline 7 & 25 & 4 & $\neq$ \\
\hline 8 & 27 & 2 & $\neq$ \\
\hline 9 & 22 & 2 & $\neq$ \\
\hline 10 & 34 & 3 & $\neq$ \\
\hline 11 & 35 & 3 & $\neq$ \\
\hline 12 & 26 & 2 & $\begin{array}{l}\text { Marked adhesion during } \\
\text { laparoscopy }\end{array}$ \\
\hline 13 & 28 & 3 & Uterine wall rupture \\
\hline 14 & 29 & 2 & $\neq$ \\
\hline 15 & 30 & 3 & $\neq$ \\
\hline 16 & 33 & 4 & $\neq$ \\
\hline 17 & 34 & 4 & $\neq$ \\
\hline 18 & 23 & 2 & $\neq$ \\
\hline 19 & 36 & 5 & Uterine wall rupture \\
\hline 20 & 37 & 6 & Uterine wall rupture \\
\hline 21 & 34 & 4 & $\neq$ \\
\hline 22 & 27 & 2 & $\neq$ \\
\hline 23 & 32 & 3 & Placenta percrreta \\
\hline 24 & 35 & 4 & Placenta percrreta \\
\hline 25 & 39 & 4 & Caesarean section myomectomy \\
\hline & & & \\
\hline
\end{tabular}

\section{Operative details}

In our procedure here only one side was devacularized and therefore good blood supply from other side or from anastomosis below was confirmed.

Lower down vaginal operative steps were followed during all previous difficult cases which were 25 cases consist of: first step is to stop bleeding by application of artery forceps at site of uterine artery injury or tear; meticulous adhesiolysis was done to permit clear field for repair of tear of uterine wall or injured, slipped uterine artery; cutting and ligation of infundublopelvic ligament from lateral pelvic wall and ligation and hemostasis around the knot; cutting in incisional way the broad ligament below the separated infundopelvic ligament to create big adequate space for control of any type of bleeding; start perfect ligation or suturing of the defect or tear in uterine wall about $1 \mathrm{~cm}$ below lower edge of the tear or hematoma and this after counter action of the uterus by assistant and this will be in ease due to availability of wide space and clear anatomy; in case of low or very low ligation of slipped uterine artery to control big hematoma, fine and meticulous dissection in the medial leave of the broad ligament to explore over the ureter and to confirm its patency and absence of its transection or before or during control of bleeding; the suture material used in all cases was vicryl zero; all cases management under spinal anesthesia except case of missed IUCD was done under general anesthesia during tracing of missed IUCD by laparoscopy and then shifted to laparotomy; and all cases received 2 gram of cefazone antibiotic (cephaprazone) (Epico pharmaceutical company) before the operation by half hour mixed with $500 \mathrm{cc}$ normal saline infusion plus 1 gm kapron (tranexamic acid).

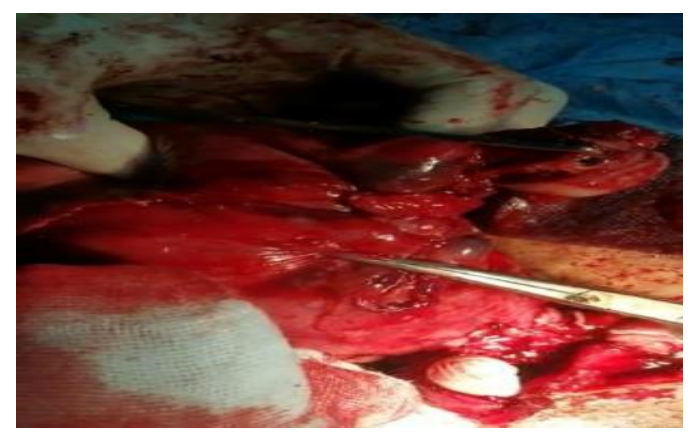

Figure 1: First view left infundublectomy during control of bleeding during left uterine artery injury during difficult caesarean section due to marked adhesion.

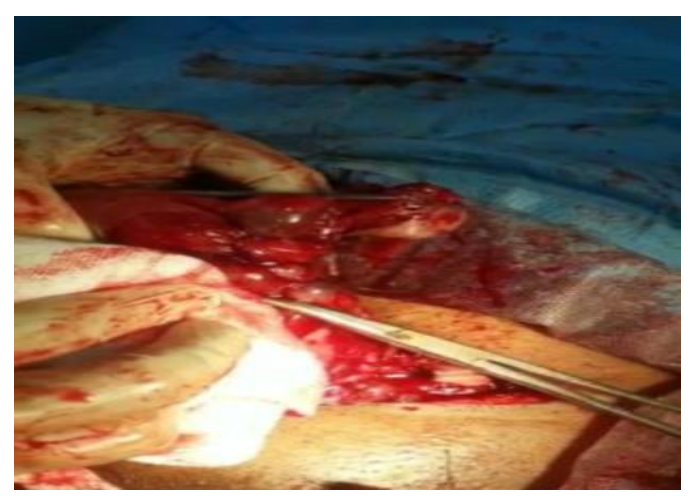

Figure 2: Second view left infundublectomy during control of bleeding during left uterine artery injury during difficult cesarean section due to marked adhesion. 


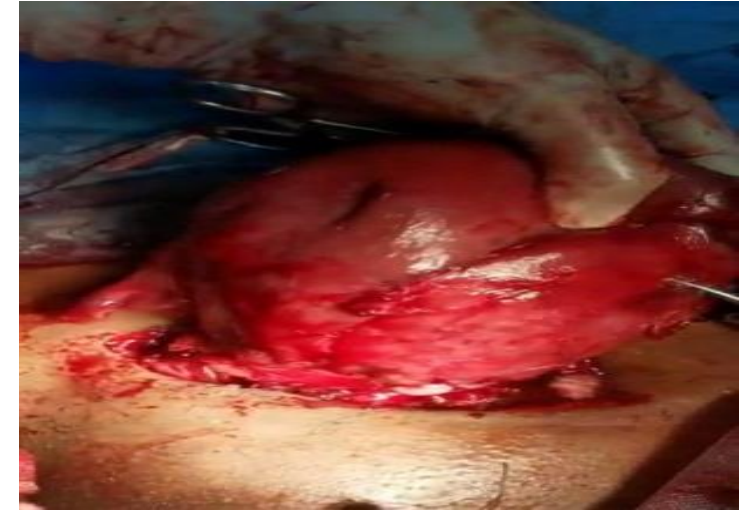

Figure 3: Third view left infundublectomy during control of bleeding during left uterine artery injury during difficult caesarean section due to marked adhesion.

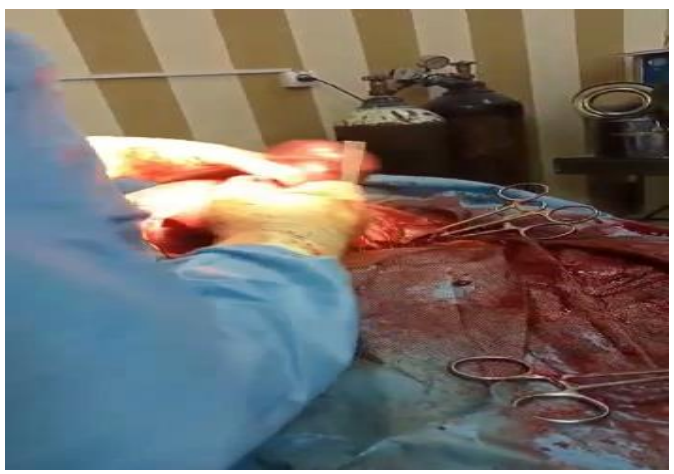

Figure 4: First view left infundublectomy trying to prevent intraoperative bleeding and post-partum hemorrhage by ligation of left uterine artery during caesarean section myomectomy.

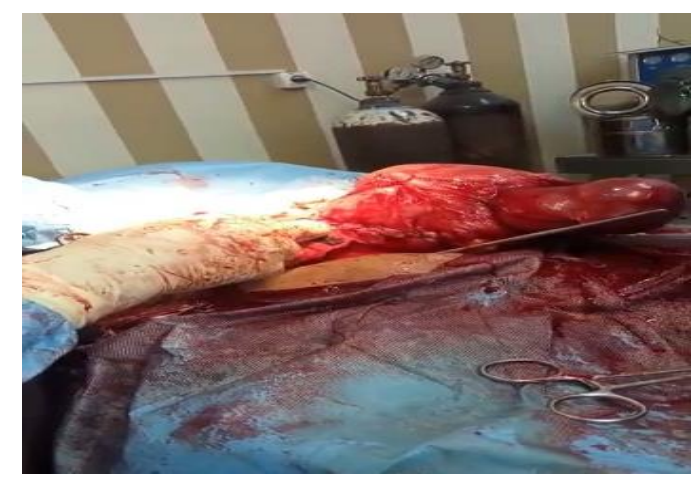

Figure 5: Second view left infundublectomy trying to prevent intraoperative bleeding and post-partum hemorrhage by ligation of left uterine artery during caesarean section myomectomy.

\section{Short term outcomes}

It included: no need for hysterectomy; 6 cases need blood transfusion of 2 units of packed red blood cells (RBCs), one case of rupture uterus and two cases of severe adhesion requiring adhesiolysis and resulting in injuries of uterine artery at left side, one case of caesarean section myomectomy, 2 cases of placenta percrreta; no bladder nor ureteric injury except in 2 cases of placenta accrete as injuries occurred above junction of left ureter with bladder by $2 \mathrm{~cm}$ and managed by insertion of double $J$ catheter and suturing of the small ureteric defect without opening of the bladder; no intestinal or colonic injuries in spite of high rates of severe adhesion in cases of repeat CS; and no postpartum hemorrhage either primary or secondary good post-partum with normal blood discharge (lochia) except, in one case of course rupture uterus where ligature of lower uterine segment obstruct the flow and insertion of Foleys catheter intrauterine allow good flow of retained blood with complete resolution of collected blood followed by complete uterine involution.

\section{Intra and postoperative management}

It included: no blood transfusion intra operative; broad spectrum antibiotics were given in the form augram (amoxicillin and glavulanic acid) one gm orally three times daily (2 packets) plus garamycin $80 \mathrm{mg}$ intramuscular three times daily for 3 days plus amirazol one gram rectal suppository 3 times daily for 3 days; follow up of vital signs and urine output until confirmation that no intra nor post-operative bleeding; adominal ultrasonography was done for every case for more confirmation that no intra-abdominal bleeding; and (b) post-operative complication like bladder injuries or ureteric and managed accordingly.

Follow up of hematological parameters revealed that presence of decreased in hemoglobin $(\mathrm{Hb})$ in all cases the average level of $\mathrm{Hb}$ was not less than $8 \mathrm{~g} / \mathrm{dl}$ and these cases were treated by parenteral intravenous sacrofer about seven ampoules in gradual course followed by intra muscular haemaget in home plus oral lactoferrin (pravotin) sachets daily until $\mathrm{Hb}$ became normal $(11 \mathrm{~g} / \mathrm{dl})$.

\section{Postoperative briefing}

After operation and after complete follow up and confirmation that no post-partum complication especially absence of post-partum hemorrhage, detailed explanation what has happened and what steps were done and their sequels and essential follow up after that for patient and her relatives.

\section{Long term outcomes}

It included: normal menstrual flow in all case in pattern and amount in all cases; normal post-partum involution of the uterus regarding duration of post-partum follow up by abdominal and vaginal ultra-sonography; normal blood flow in Doppler studies in the side of infudeblectomy which was mostly left side with no affection neither in upper or lower part of the side of the uterus; and fertility was normal occurring in all cases with good conception and normal antenatal care but follow up and mode of deliveries was not registered. 


\section{DISCUSSION}

Regarding to the previous procedure, as it was done in urgent way to control bleeding and to save life of the patient and also save reproductive capability, and as very little literature were found in web sites regarding trauma, injuries complication during caesarean section, it is considered as original procedure done in this sequel.

It was difficult to compare it to another procedure as most of the other procedures were designed to manage cases of placenta accrete spectrum and how to control bleeding either by conservative procedures or radical ones.

It was founded useful in some cases of placenta acrreta spectrum where conservation of uterus is essentially needed especially in Christian religion link where the wife is permanent one and importance of preserve uterus to maintain fertility in young age and continue to deliver.

This were previously studied in case series trial for conservative management of uterus as author described that his conservative method avoid radical management of placenta accreta spectrum in which was associated with high morbidity and mortality and avoid psychological problems after hysterectomy and improved marital relationship which depend upon preserved fertilization. ${ }^{4}$

It was useful in cases of caesarean section myomectomy where bilateral ligation also of uterine arteries is very important especially in presence of massive adhesion between uterus and bladder and lateral pelvic wall.

\section{CONCLUSION}

This study was done for cases associated with difficult reaching to uterine artery after its injury and formation of big hematoma or slippage downward in base of broad ligament either in right or left side, or in case of big uterine side tear due to one side rupture or big area defect during managing case of placenta accrete spectrum.

The difficulties in managing these cases always were narrow space or in- acceptability to uterine artery due to presence of infundibulopelvic ligament and broad ligament at site of uterine artery bleeding or uterine wall tear.

Our ideas came from previous studies and trials that bilateral ligation of uterine arteries did not affect vascularization of uterus and even complete devascularization of uterus is associated with return of good blood supply through blood supply from anastomosis between branches from femoral arteries (extension of external arteries in thigh) supplying and anastomose with branches from vaginal arteries (branch from internal iliac artery) and forming iliac vaginal arcades. In our procedure here only one side was de-vacularized and therefore, good blood supply from other site or from vaginal arcades anastomosis below was confirmed.

Our case series procedure result in good outcomes regarding control of bleeding in difficult cases mentioned and indicated also in conservation of uterus in the same cases.

\section{Funding: No funding sources \\ Conflict of interest: None declared \\ Ethical approval: Not required}

\section{REFERENCES}

1. Nisenblat V, Barak S, Griness OB, Degani S, Ohel G, Gonen R. Maternal complications associated with multiple cesarean deliveries. Obstet Gynecol. 2006;108(1):21-6.

2. Lakshmi JV, Anuradha C, Rishith M. Intra-operative complications in repeat cesarean sections. Int J Clin Obstet Gynecol. 2020;4(2):144-9.

3. Amale S, Bhirud A, Sarode P, Study of intraoperative complications in lower segment caesarean section at tertiary care hospital Med Pulse. Int J Gynaecol. 2021;19(1):6-9.

4. Mitwally ABA, Abass AM. Sequential surgical steps for conservative management of morbidly adherent placenta. Case series. Thai J Obstet Gynecol. 2016;24:136-40.

Cite this article as: Mitwally ABA.

Infundebulectomy in management of uterine artery or uterine wall injury during complicated and difficult caesarean section: case series study. Int J Reprod Contracept Obstet Gynecol 2022;11:595-8. 